\title{
Key performance indicators for stroke from the Ministry of Health of Brazil: benchmarking and indicator parameters
}

\author{
Indicadores de performance de AVC do Ministério da Saúde do Brasil: avaliação \\ comparativa e parametrização dos indicadores \\ Marcos C Lange', Gabriel Pereira Braga², Edison M Nóvak', Rodrigo Harger', \\ Maria Justina Dalla Bernardina Felippe², Mariana Canever'1, Isabella Dall'Asta', Jordana Rauen', \\ Rodrigo Bazan², Viviane Zetola
}

\begin{abstract}
The present study aimed to analyze the stroke units in two centers for the key performance indicators (KPIs) required by the Ministry of Health in Brazil. Methods: All $16 \mathrm{KPls}$ were analyzed, including the percentage of patients admitted to the stroke unit, venous thromboembolism prophylaxis in the first 48 hours after admission, pneumonia and hospital mortality due to stroke, and hospital discharge on antithrombotic therapy in patients without cardioembolic mechanism. Results: Both centers admitted over $80 \%$ of the patients in their stroke unit. The incidence of venous thromboembolism prophylaxis was $>85 \%$, that of in-hospital pneumonia was $<13 \%$, the hospital mortality for stroke was $<15 \%$, and the hospital discharge on antithrombotic therapy was $>70 \%$. Conclusion: Our results suggest using the parameters of all of the $16 \mathrm{KPIs}$ required by the Ministry of Health of Brazil, and the present results for the two stroke units for future benchmarking.
\end{abstract}

Keywords: stroke; quality indicators, health care; delivery healthcare; outcome and process assessment; health care.

\section{RESUMO}

O objetivo do presente estudo é analisar os indicadores de qualidade (IQ) exigidos pelo Ministério da Saúde no Brasil em duas unidades de AVC. Métodos: Foram analisados os 16 IQ, incluindo a percentagem de pacientes internados na unidade de AVC, profilaxia de tromboembolismo venoso (TEV) nas primeiras 48 horas após a admissão; pneumonia e mortalidade hospitalar e alta hospitalar em terapia antitrombótica (TAT) em pacientes sem mecanismo cardioembólico. Resultados: Ambos os centros admitiram mais de $80 \%$ dos pacientes na unidade de AVC. A profilaxia do TEV foi realizada em mais de 85\% dos casos; a pneumonia hospitalar foi inferior a 13\%; a mortalidade hospitalar foi menor que $15 \%$ e a alta hospitalar em uso de TAT foi acima de 70\%. Conclusão: 0 presente estudo sugere os parâmetros dos $16 I Q$ exigidos pelo Ministério da Saúde do Brasil e os resultados obtidos em duas unidades de AVC para avaliação comparativa futura

Palavras-chave: acidente vascular cerebral; indicadores de qualidade em assistência à saúde; assistência à saúde; avaliação de processos e resultados; cuidado da saúde.

Stroke is one of the leading causes of mortality and morbidity worldwide. To improve this scenario, it is crucial to evaluate reliable data to improve the standards of hospital care, since quality care is of great value in the prognosis of patients ${ }^{1,2}$.

In 2012, the Brazilian Ministry of Health published Resolution No. 665 for implementation in stroke treatment, including the implementation of stroke units ${ }^{3}$. An essential aspect of this regulation was the inclusion of key performance indicators (KPIs) for monitoring disease management in all the comprehensive stroke units ${ }^{3}$.
The present study aimed to demonstrate the analysis of the KPIs determined by the Brazilian Ministry of Health in two separate Brazilian stroke units, and to suggest parameters to consider while evaluating the different metrics.

\section{METHODS}

This was a retrospective and descriptive study performed in two public tertiary hospitals in Brazil, the Hospital das

\footnotetext{
'Universidade Federal do Paraná, Hospital de Clínicas, Curitiba PR, Brasil;

Universidade do Estado de São Paulo, Hospital das Clínicas, Botucatu SP, Brasil.

Correspondence: Marcos C Lange; Hospital de Clínicas, Serviço de Neurologia; Rua General Carneiro, 181 / 4º andar; $80060-900$ Curitiba PR, Brasil; E-mail: langeneuro@gmail.com

Conflict of interest: There is no conflict of interest to declare.

Received 18 July 2016; Received in final form 29 December 2016; Accepted 15 February 2017.
} 
Clinicas from São Paulo State University in Botucatu, and the Hospital de Clinicas from the Federal University of Parana in Curitiba. The ethics committees of both hospitals approved this study.

All the patients with a confirmed stroke diagnosis admitted from January 2015 to June 2015 were included in the study. The following exclusion criteria were considered: 1) length of stay < 2 days; 2) "comfort measures only" documented on days 0 or 1 ; 3) enrolled in clinical trials related to stroke; 4) left against medical advice on days 0 or $1 ; 5$ ) died on day 0 or 1 ; and 6) length of stay > 120 days.

The definition of a stroke unit used in the current study was a multidisciplinary team comprising physicians, clinical nurses, physical therapists, occupational therapists, and speech and language therapists in a specific ward providing specialized care to patients with stroke ${ }^{4}$. The stroke unit is characterized as a semi-intensive unit, and the only criterion to be admitted to a stroke unit was the diagnosis of stroke, independent of the severity. The criteria to not be admitted to the stroke unit were: 1) unconscious patients; 2) necessity of mechanical ventilation; 3) presence of hemodynamic instability; and 4) patients who underwent a surgical procedure (e.g., craniectomy). All the patients were admitted to the intensive care unit.

The 16 KPIs published by the Ministry were considered in four groups: the admission KPIs, the in-hospital treatment KPIs, the in-hospital complication KPIs, and the discharge KPIs. The admission KPIs considered were as follows: 1) door-to-image time < 25 minutes, 2) door-to-needle time $<60$ minutes, and 3) percentage of patients admitted to the stroke unit, which was the only marker considered for all the patients with stroke admitted to the hospital during the study period. The in-hospital treatment KPIs were as follows: 1) venous thromboembolism prophylaxis in the first 48 hours after admission and 2) antithrombotic therapy by the end of day 2. The in-hospital complication KPIs were: 1 ) deep venous thrombosis, 2) pressure ulcer, 3) pneumonia, 4) urinary tract infection, and 5) hospital mortality. The discharge KPIs were the following: 1) hospital discharge on antithrombotic therapy in patients without cardioembolic mechanism, 2) hospital discharge on anticoagulation therapy in patients with atrial fibrillation or flutter, 3) hospital discharge on statin therapy in patients with atherothrombotic mechanisms, 4) hospital discharge on rehabilitation and secondary prevention therapy in patients with ischemic stroke, 5) mean length (in days) of the hospital stay for patients with stroke, and 6) specific ICD-10 for stroke etiology at discharge. Table 1 presents the parameters for all the KPIs considered in the current study based on previous publications ${ }^{5,6,7,8,9}$.

All the data were collected prospectively and manually at patient admission in a standard flowchart and checklist by a professional from the stroke unit. After discharge, the information was reviewed by an external professional and confirmed by checking the patient admission records. The absence of data was considered as "procedure not followed."
Descriptive analysis of the qualitative variables was performed using simple frequencies and percentages.

\section{RESULTS}

This study included 117 patients with stroke admitted to the Federal University of Paraná and 172 patients admitted to the São Paulo State University. All the patients had complete data for analyses. Ischemic stroke etiology was found in $106(90.5 \%)$ cases at the Federal University of Parana and $149(86.6 \%)$ cases at the São Paulo State University. The mean length (in days) of hospital stay for the patients with stroke was six and 12 days in the São Paulo State University and Federal University of Parana, respectively. Table 2 presents the proportions of patients in each center that achieved the KPIs.

\section{DISCUSSION}

The current study demonstrated the viability of collecting and analyzing KPIs in two different Brazilian stroke centers, including data ranging from admission until discharge. In addition, the parameters used were standard for both the centers, thereby allowing for national and international benchmarking.

The Ministry of Health KPI is the first Brazilian initiative to evaluate quality parameters in Brazil. They include 16 measures related to the structure, process, outcome, and efficiency of acute stroke care ${ }^{7}$. More than 40 measures have been previously suggested and reported, including local, national, and regional measures ${ }^{2,6,7,9,10}$. The importance of these measures lies in their capability to evaluate individual facilities over time, compare the qualities of different healthcare providers, and identify areas for improvement ${ }^{10}$.

When considering the admission KPI, a recent study demonstrated that $68 \%$ of the patients achieved the door-to-image time ${ }^{11}$. In the present study, the door-to-image time was very different in both the centers, which could be related to the patient admission flow for early stroke management. In one of the centers (Federal University of Paraná), the patients were admitted directly in the CT room, thereby significantly reducing the door-to-image time ${ }^{12}$. This demonstrated the importance of identifying gaps in the timeline of acute stroke care, from symptom identification by the patient and/or relatives to discharge from hospital. Even with this discrepancy, two-thirds of the patients achieved the door-to-needle in both centers, higher than previously reported ${ }^{11}$. One important result is that more than $80 \%$ of patients were admitted to a stroke unit in the current study, very similar to previous studies ${ }^{13,14}$. The admission to a stroke unit is an important marker to evaluate the performance and outcome of hospitals. In this ward, patients are treated by 
Table 1. Parameters for the key performance indicators considered in the current study.

\begin{tabular}{|c|c|c|}
\hline $\mathrm{KPI}$ & Definition & Method \\
\hline $\begin{array}{l}\text { Venous } \\
\text { thromboembolism } \\
\text { (VTE) prophylaxis in } \\
\text { the first } 48 \text { hours after } \\
\text { admission }\end{array}$ & $\begin{array}{l}\text { Percentage of patients } \\
\text { prescribed VTE } \\
\text { prophylaxis on hospital } \\
\text { days } 0 \text { or } 1\end{array}$ & $\begin{array}{l}\text { Based on prospective } \\
\text { data from patient } \\
\text { medical records }\end{array}$ \\
\hline
\end{tabular}

Numerator Denominator

Important points

Patients with ischemic

documentation related

was not provided

Hospital discharge on
antithrombotic therapy Percentage of

antithrombotic therapy patients without
(ATT) in patients

without cardioembolic

CE mechanisms

(CE) mechanisms

discharged on ATT

Based on prospective data from patient medical records

Hospital discharge on Percentage of patients anticoagulation therapy with atrial fibrillation in patients with atrial fibrillation or flutter or flutter discharged on anticoagulation

Based on prospective data from patient medical records

The ATT at the end of
day 2

Percentage of patients Based on prospective with ischemic stroke on data from patient ATT at the end of day 2 medical records

Hospital discharge on statin therapy in patients with atherothrombotic mechanisms

Hospital discharge on rehabilitation and secondary prevention therapy in patients with ischemic stroke

Percentage of patients admitted to the

stroke unit

Mean time (in days) of hospital stay for patients with stroke

Deep venous thrombosis (DVT)

Pressure ulcer (PU)

Percentage of patients with atherothrombotic mechanisms discharged on statins

Based on prospective data from patient medical records

Percentage of patients with ischemic stroke discharged on rehabilitation and secondary prevention therapy

Based on prospective data from patient medical records

Percentage of patients Based on prospective with stroke admitted to data from patient the Stroke Unit medical records

Mean time (in days) of hospital stay for patients with stroke

Percentage of patients with ischemic stroke with DVT at admission Percentage of patients with ischemic stroke with PU at admission

Percentage of patients with ischemic stroke with pneumonia at admission

Pneumonia Urinary tract infection
(UTI)

Percentage of patients with ischemic stroke with UTI at admission

Percentage of patients

Specific ICD-10 to stroke etiology at discharge discharged with stroke admitted to the stroke unit with the specific ICD-10 to stroke etiology

Percentage of patients

Hospital mortality due to stroke with stroke who died during hospital admission

Based on prospective data from patient medical records

Based on prospective data from patient medical records

Based on prospective data from patient medical records

Based on prospective data from patient medical records

Based on prospective data from patien medical records

Based on prospective data from patient medical records

Based on prospective data from patient medical records

Percentage of patients with ischemic stroke Based on prospective less than 25 minutes of medical records admission

Percentage of

patients with ischemic Based on prospective stroke submitted to data from patient thrombolysis in less than medical records 60 minutes of admission
Door-to-needle time $<60$ minutes stroke prescribed

VTE prophylaxis in

the first 48 hours

after admission

or those who have

to why VTE prophylaxis

All patients with

ischemic stroke

Patients with ischemic All patients with stroke without CE mechanisms discharged on ATT ischemic stroke without CE mechanisms

\section{Patients with}

ischemic stroke with atrial fibrillation or flutter discharged on anticoagulation

Patients with ischemic stroke who are prescribed ATT at the end of day 2

Patients with

ischemic stroke with atherothrombotic

mechanisms

discharged on statins

All patients with ischemic stroke with atrial fibrillation or flutter

Patients with ischemic stroke discharged on rehabilitation and secondary prevention therapy

Patients with stroke admitted to the stroke unit

Mean time (in days) of hospital stay for patients with stroke

Patients with ischemic stroke with DVT at admission

All patients with ischemic stroke

All patients with ischemic stroke with atherothrombotic mechanisms

All patients with ischemic stroke

Documented in the patient's file (heparin, low-molecularweight heparin) or intermittent pneumatic compression. Reasons not to introduce: the patient was ambulatory or undergoing full-dose anticoagulation for other reasons

Antiaggregation or anticoagulation medication in therapeutic dosage considered

Anticoagulation medication in therapeutic dosage considered

Antiaggregant or anticoagulation medication in therapeutic dosage considered

At least $50 \%$ stenosis to considered atherothrombotic mechanisms

Patients with ischemic stroke with PU at admission

Patients with ischemic stroke with pneumonia at admission

Patients with ischemic stroke with UTI at admission

Percentage of patients discharged with stroke admitted to the stroke unit with the specific ICD-10 to stroke etiology Percentage of patients with stroke who died during hospital admission

Percentage of patients with ischemic stroke submitted to brain CT in less than 25 minutes of admission

Percentage of patients with ischemic stroke submitted to thrombolysis in less than thrombolysis and 60 minutes of admission admitted to the hospital

KPI: key performance indicators; NA: not available; VTE: venous thromboembolism; ATT: antithrombotic therapy; SU: stroke unit; CE: cardioembolic; DVT: deep venous thrombosis; PU: pressure ulcer; UTI: urinary tract infection; DTI: door-to-image; DTN: door-to-needle. 
Table 2. Percentage of patients in each center that achieved the key performance indicators.

\begin{tabular}{|c|c|c|}
\hline \multirow{2}{*}{ Variable } & SPSU & FUPR \\
\hline & (\%) & (\%) \\
\hline DTI & 27 & 83 \\
\hline DTN & 75 & 66 \\
\hline DVT prophylaxis on day 2 & 92 & 88 \\
\hline Antiplatelet therapy on day 2 & 97 & 94 \\
\hline $\begin{array}{l}\text { Antiplatelet therapy at discharge in } \\
\text { non-cardioembolic IS }\end{array}$ & 75 & 100 \\
\hline $\begin{array}{l}\text { Anticoagulation therapy at discharge in } \\
\text { cardioembolic (atrial fibrillation) IS }\end{array}$ & 94 & 87 \\
\hline Statin at discharge in atherothrombotic IS & 100 & 88 \\
\hline Plan of rehabilitation and prophylaxis at discharge & 96 & 87 \\
\hline $\begin{array}{l}\text { Percentage of stroke patients admitted to the } \\
\text { stroke unit }\end{array}$ & 94 & 84 \\
\hline DVT & 0.6 & 0.0 \\
\hline Pneumonia & 13 & 6 \\
\hline UTI & 11 & 6 \\
\hline PU & 0.6 & 1 \\
\hline Mortality rate & 8 & 14 \\
\hline Specific ICD-10 to stroke etiology at discharge & 24 & 64 \\
\hline
\end{tabular}

SPSU: Sao Paulo State University; FUPR: Federal University of Paraná; DTI: door-to-image time; DTN: door-to-needle time; DVT: deep venous thrombosis; IS: ischemic stroke; UTI: urinary tract infection; PU: pressure ulcer; ICD: International code diagnosis.

a multidisciplinary team specialized in their condition, and this could reduce clinical complications during admission and improve the outcome after discharge.

For the in-hospital treatment KPIs, two important factors related to mortality and disability after stroke were evaluated, venous thromboembolism prophylaxis and antithrombotic therapy. These reached approximately $90 \%$ in both the centers, which was very similar to the previously reported national and international data ${ }^{15,16}$.
Clinical complications are common after stroke; $16 \%$ of the patients develop urinary tract infection, $11.2 \%$ develop chest infection, $0.6 \%$ develop deep venous thrombosis, and $0.6 \%$ develop pressure ulcer ${ }^{17}$. In the current study, the incidence of these complications was very similar to that reported by previous studies. The mortality rate presented in our study is lower than that previously published in Brazilian epidemiological studies ${ }^{18,19}$.

When the discharge KPIs were analyzed, the antithrombotic therapy at discharge in patients without cardioembolic mechanisms, hospital discharge on anticoagulation therapy in patients with atrial fibrillation or flutter, and hospital discharge on statin therapy in patients with antithrombotic therapy mechanisms were those prescribed in more than $75 \%$ of the patients in both the centers. Previous studies showed higher numbers, with more than $88 \%$ for these important secondary prevention parameters ${ }^{10,18,19}$.

Usually, the set of measures does not include all the worthwhile clinical interventions; some of these are challenging to measure or to define in acute stroke settings. The refinement of measures is an ongoing process, and changes can be expected ${ }^{7}$. Hence, some important outcome markers should be considered while reviewing the current KPIs, such as patient education, percentage of patients submitted to thrombolysis, assessment of dysphagia, counseling for smoking cessation, outcomes, and complications after discharge $\mathrm{e}^{5-10,14,20}$.

Some important limitations of this study are as follows. The analyses were performed in only two public academic centers in south and southwest Brazil. The results could be different in other private or non-academic centers, or in other regions of the country. The data presented here, and the suggestions for parameters to use for the different metrics would help initiative new studies in this area and improve the benchmarking of stroke care in Brazil. At present, it is not possible to extrapolate the present data to private and non-academic centers. In a previous study performed in a private Brazilian center, the authors evaluated international performance indicators, some of which were similar to the KPIs reported here, which were compared with the studied centers ${ }^{16}$.

This is the first study in Brazil to consider the KPIs proposed by the Brazilian Ministry of Health for stroke centers, thereby highlighting their practical viability. This organized recording method could be useful for all hospitals to examine their data and improve their quality of care in the future.

\section{References}

1. Hankey GJ, Warlow CP. Treatment and secondary prevention of stroke: evidence, costs, and effects on individuals and populations. Lancet. 1999;354(9188)1457-63. https://doi.org/10.1016/S0140-6736(99)04407-4

2. Lindsay P, Furie KL, Davis SM, Donnan GA, Norrving B. World Stroke Organization global stroke services guidelines and action plan. Int J Stroke. 2014;9 Suppl A100:4-13. https://doi.org/10.1111/ijs.12371

3. Ministério da Saúde (BR). Portaria Nº 665, de 12 de abril de 2012. Dispõe sobre os critérios de habilitação dos estabelecimentos hospitalares como Centro de Atendimento de Urgência aos Pacientes com Acidente Vascular Cerebral (AVC), noâmbito do Sistema Único de Saúde (SUS),institui o respectivo incentivo financeiro e aprova a Linha de Cuidados em AVC. Diário Oficial União. 2012 Apr 13.

4. European Stroke Organisation (ESO) Executive Committee; ESO Writing Committee. Guidelines for management of ischaemic stroke and transient ischaemic attack 2008. Cerebrovasc Dis. 2008;25(5):457-507. https://doi.org/10.1159/000131083 
5. Smith EE, Saver JL, Alexander DN, Furie KL, Hopkins LN, Katzan IL et al. Clinical performance measures for adults hospitalized with acute ischemic stroke: performance measures for healthcare professionals from the American Heart Association/American Stroke Association. Stroke. 2014;45(11):3472-98.https://doi.org/10.1161/STR.0000000000000045

6. Holloway RG, Vickrey BG, Benesch C, Hinchey JA, Bieber J, Hill MD et al. Development of performance measures for acute ischemic stroke. Stroke. 2001;32(9):2058-74.

7. Reeves MJ, Parker C, Fonarow GC, Smith EE, Schwamm LH. Development of stroke performance measures: definitions, methods, and current measures. Stroke. 2010;41(7):1573-8. https://doi.org/10.1161/STROKEAHA.109.577171

8. Wiedmann S, Norrving B, Nowe T, Abilleira S, Asplund K, Dennis $M$ et al. Variations in quality indicators of acute stroke care in 6 European countries: the European Implementation Score (EIS) Collaboration. Stroke. 2012;43(2):458-63. https://doi.org/10.1161/STROKEAHA.111.628396

9. Norrving B, Bray BD, Asplund K, Heuschmann P,

Langhorne P, Rudd AG et al. Cross-national key performance measures of the quality of acute stroke care in Western Europe. Stroke. 2015;46(10):2891-5. https://doi.org/10.1161/STROKEAHA.115.008811

10. Heuschmann PU, Biegler MK, Busse O, Elsner S, Grau A, Hasenbein $U$ et al. Development and implementation of evidence-based indicators for measuring quality of acute stroke care: the quality undicator board of the German Stroke Registers Study Group (ADSR). Stroke. 2006;37(10):2573-8. https://doi.org/10.1161/01.STR.0000241086.92084.c0

11. Sauser K, Levine DA, Nickles AV, Reeves MJ. Hospital variation in thrombolysis times among patients with acute ischemic stroke: the contributions of door-to-imaging time and imaging-to-needle time. JAMA Neurol. 2014;71(9):1155-61. https://doi.org/10.1001/jamaneurol.2014.1528

12. Tansini G, Ducci RD, Nóvak EM, Germiniani FM, Zétola VF, Lange MC. Exclusive bed for thrombolysis: a simple measure that allows $85 \%$ of ischemic stroke patients to be treated in the first hour. Arq Neuropsiquiatr; 2016;74(5):373-5. https://doi.org/10.1590/0004-282X20160048

13. Turner M, Barber M, Dodds H, Dennis M, Langhorne P, Macleod MJ. Stroke patients admitted within normal working hours are more likely to achieve process standards and to have better outcomes. J Neurol Neurosurg Psychiatry. 2016;87(2):138-43. https://doi.org/10.1136/jnnp-2015-311273

14. Hall RE, Khan F, Bayley MT, Asllani E, Lindsay P, Hill MD et al. Benchmarks for acute stroke care delivery. Int J Qual Health Care. 2013;25(6):710-8. https://doi.org/10.1093/intqhc/mzt069

15. Schwamm LH, Fonarow GC, Reeves MJ, Pan W, Frankel MR, Smith EE et al. Get with the guidelines-stroke is associated with sustained improvement in care for patients hospitalized with acute stroke or transient ischemic attack. Circulation. 2009;119(1):107-15. https://doi.org/10.1161/CIRCULATIONAHA.108.783688

16. Carvalho FA, Schwamm LH, Kuster GW, Alves MB, Cendoroglo Neto M, Silva GS. Get with the guidelines stroke performance indicators in a brazilian tertiary hospital. Cerebrovasc Dis Extra. 2012;2(1):26-35. https://doi.org/10.1159/000339578

17. Indredavik B, Rohweder G, Naalsund E, Lydersen S. Medical complications in a comprehensive stroke unit and an early supported discharge service. Stroke. 2008;39(2):414-20. https://doi.org/10.1161/STROKEAHA.107.489294

18. Cabral NL, Gonçalves AR, Longo AL, Moro CH, Costa G, Amaral CH et al. Trends in stroke incidence, mortality and case fatality rates in Joinville, Brazil: 1995-2006. J Neurol Neurosurg Psychiatry. 2009;80(7):749-54. https://doi.org/10.1136/jnnp.2008.164475

19. Carvalho JJ, Alves MB, Viana GA, Machado CB, Santos BF, Kanamura $\mathrm{AH}$ et al. Stroke epidemiology, patterns of management, and outcomes in Fortaleza, Brazil: a hospital-based multicenter prospective study. Stroke. 2011;42(12):3341-6. https://doi.org/10.1161/STROKEAHA.111.626523

20. Kapral MK, Laupacis A, Phillips SJ, Silver FL, Hill MD, Fang J et al. Stroke care delivery in institutions participating in the Registry of the Canadian Stroke Network. Stroke. 2004;35(7):1756-62. https://doi.org/10.1161/01.STR.0000130423.50191.9f 